\title{
Product Platforms and Production - Current State and Future Research Directions Targeting Producibility and Production Preparation
}

\author{
Rohith ARETH KOROTH ${ }^{1}$, Martin LENNARTSSON , Dag RAUDBERGET and Fredrik \\ ELGH \\ School of Engineering, Jönköping University, Sweden
}

\begin{abstract}
New business opportunities are created when the advantage of changeable manufacturing systems expand beyond increased freedom in production location to increased freedom in product design. However, there are new challenges to overcome, including improved ability to design and adapt products when requirements from stakeholders quickly change and/or new technology rapidly evolves. Simultaneously, the producibility of each design must be ensured while keeping the lead-time of the whole process to the minimum. Changeable product platforms (both flexible and adaptable platforms) are gaining attention in both research and industry. However, the level of alignment and integration of product development and production is critical for the efficiency of the product realization process. In this study, we map the state of practice in five companies with an initial literature review. The companies had no formal platform strategy and faced challenges with variant management and development time, had manual processes for production preparation and reuse of technical solutions and knowledge happened through components and documents. The production preparation and reuse were dependent on the engineer's competence. Future work will concentrate on identifying how manufacturing inputs can be added as a design asset in a changeable product platform to enhance producibility and production preparation.
\end{abstract}

Keywords. Product Platform, Production, Producibility, Production Preparation, Transdisciplinary Approach

\section{Introduction}

The uncertainties and design freedom in the early phases of product development lead to challenges such as the gradual definition of product characteristics, uncertainties in product mix due to long lead time, high product complexity, product variations and a solution space that is not predefined $[1,2]$. The uncertainties in factors such as product mix and volume necessitate increasing the responsiveness of the company to changing conditions in all operations including design and production [3]. Reusing past solutions and designs in new designs will help to reduce the uncertainties [4], lead-time and cost. The product platform concept has been identified to support this reuse of assets such as component design [5].

Support is required for improved ability to design and adapt products when requirements from stakeholders change quickly and/or new technology evolves rapidly. Simultaneously, the producibility of each design must be ensured while keeping the lead-time of the whole

\footnotetext{
${ }^{1}$ Corresponding Author, Mail: rohith.arethkoroth@ju.se.
} 
process to a minimum. Changeable product platforms is an emerging topic in research and industry. The level of alignment and integration of specific product platforms and production is critical for the efficiency of the product realization process. Production preparation through methods such as Design for Manufacture will develop a collective understanding of product design and manufacturing [6]. It is necessary to include producibility aspects in the early phases of development to support flexibility and remove costly modifications during later phases [7].

In this study, the state of practice in five companies is mapped with a frame of reference on methods and practices in platform-based development and production preparation. The case companies belonged to sectors such as lighting, outdoor power products, automotive and industrial house building. The current practice was analyzed from the data collected by interviews conducted with the case companies. The interviewee group was transdisciplinary with representatives from project management, new product development, design, production, purchasing, testing and quality departments. A total of fifty interviews were conducted from the five case companies. The purpose of the study is to understand the current state of practice for production preparation and identify future research directions for enhancing producibility and production preparation.

\section{Frame of reference}

Product platforms are identified as an enabler for achieving product variation and support customization [8]. Product platform definition varies from a collection of assets such as component designs which can be shared across products [9], a group of related products [10] to assets such as knowledge and relationships [5]. The benefits of platform utilization are dependent on when the customer is involved in the specification process [11]. The product specification process can be categorized into four types depending on when the customer is involved - engineer to order (ETO), modify to order (MTO), configure to order (CTO) and select variant (SV) [12]. There are fluctuations in requirements in ETOs during the early and late stages of the product development process due to continuous customer involvement [13] which results in uncertainties [14]. A platform-based development can help to achieve efficient reuse across variants while facing challenges such as an increase in the frequency of introduction of new products, change of existing parts, changes in government regulations and changes in processes [15]. Han et al. [16] propose the concept of Uncertainty-Oriented Product Platform (UOPP) to increase the adaptability of enterprises to uncertainties. UOPP includes platform models such as flexible product platform, adaptable product platform, market-driven product platform and sustainable product platform [16]. A flexible platform considers into account uncertainties and consists of flexible elements. A flexible element is an element that can accommodate changes to create product variants without large investments [17]. Flexibility is achieved by modifying the parameters of the flexible elements. The flexible platform can avoid costly redesigns and costs associated with manufacturing changes [18]. Adaptable product platforms meet the dynamically changing customer requirements using the degrees of freedom in the product and process design and generate solutions through the reuse of existing knowledge, process resources and existing product geometries [19]. We define a changeable product platform as the combination of both flexible and adaptable platform principles. One example of a changeable product platform approach is the design platform that supports the use of heterogeneous design assets [13]. The design assets can be the product, processes, knowledge (guidelines, lesson learned etc), constraints, people and relationships [20]. The design platform model proposed by 
Andre et al. [21] considers inputs from disciplines such as design engineering, project management, quality engineering, purchasing, manufacturing engineering, cost engineering and requirement engineering as resources. This approach supports the use of transdisciplinary design resources in product development.

The production preparation process (3P) is part of lean thinking which is aimed at eliminating waste during product and process design [22]. This lean 3P methodology benefits from utilizing cross-functional teams to have product or process improvement, allows for rapid testing of ideas and embeds lean manufacturing concepts into the design itself. The ability to assess producibility in multiple design alternatives will enable design engineers to make design decisions that will prevent costly redesigns later in the development by ensuring that the product family fulfils the required manufacturing conditions [23]. Producibility considerations allow the design engineers to exploit the production facilities to provide better costs and quality [24]. Approaches such as design for manufacturing (DFM) and design for assembly (DFA) provides guidelines to the designers and utilizes manufacturing inputs to assess producibility during product design [23, 25]. But, DFM focuses on process capabilities of manufacturing and this information is often lacking during the early development phases [7]. DFM requires designers to have a good understanding of the manufacturing constraints [26]. Madrid et al. classifies producibility failures and presents methods for producibility assessment. The failures can be operational failures and quality failures. The producibility assessments can be carried out by function models, design structure matrixes, using models from computer-aided design, computer-aided engineering and computer integrated manufacturing. A Manufacturability Assessment System (MAS) can be used to reduce development time by virtually checking the manufacturability of the product [27]. Heikkinen et al [28] presented a rule-based manufacturability assessment system that is automated and enabling set-based concurrent engineering (SBCE).

SBCE begins by considering a range of solutions and gradually narrowing it down to a final solution [29]. The set of feasible solutions are defined by the design and manufacturing engineers together. There are three principles to SBCE- map the design space, integration by intersection and establish feasibility before commitment [29]. The principle of mapping the design space concentrates on defining the feasible regions based on past knowledge, engineering checklists etc. and communication between the functional groups. The principle of integration by intersection target solutions that are feasible, following minimum solution constraints to maintain flexibility and robust solutions. The principle of establishing feasibility before commitment focuses on the gradual elimination of solutions based on developing knowledge, staying within the committed sets and managing the uncertainty at integrating events. The efficiency of the SBCE process is that the elimination can be done more confidently than selection based on the available knowledge [30]. Levandowski et al. [2] give an approach using SBCE principles to support the development of a platform based on functions and design solutions without compromising the range of solutions possible. This approach uses a combination of scalable and modular platforms in the preparation face.

Design automation and digitalization helps to improve the efficiency of the product development process. Design automation can be defined as the computerized automation of tasks in the design process to support the implementation and reuse of information and knowledge in solutions, tools or systems [31]. It can support design synthesis, design analysis and plan for manufacture. Design automation is of two types-information handling and knowledge processing. Digitalization supports product development through the use of digitized information such as digital guidelines, data generated during the product lifecycle [32]. Both these help to reduce costs, lead times and meet customer requirements. Heikkinen et al. [28] present an automated method for producibility analysis and Andre et al. [21] 
presents a digital platform manager to support the design of variants. These examples show the application of automation and digitalization to support product development. The advent of Industry 4.0 has opened new opportunities for digitalization and design automation. Industry 4.0 includes the concepts of smart factories, cyber-physical systems, adaptation to human needs etc [33]. It supports short development periods, individualization on demand, flexibility, decentralization and resource efficiency. Tao et al. [34] present how digital twin combined with big data can support product development. The system generates data that can support conceptual design, detailed design and virtual verification. The literature review indicates that usage of product platforms can support production preparation through the use of design assets. But the usage of product platforms is limited in the ETOs at present.

\section{Current industrial practice}

The study for current industrial practice was conducted to understand the challenges faced in the industries during product development, production preparation and the usage of product platforms to enhance producibility. A collaboration project was formed with five companies participating in a $3 \frac{1}{2}$-year research project. The five case companies under investigation represented a wide sample group with business areas of lighting, automotive, power products and construction. This selection allowed the study to identify challenges and draw conclusions that apply in general to the industries.

Table 1: Company description and interview details

\begin{tabular}{|l|l|l|l|}
\hline $\begin{array}{l}\text { Company } \\
\text { (Business) }\end{array}$ & $\begin{array}{l}\text { Specification } \\
\text { process }\end{array}$ & $\begin{array}{l}\text { No. of } \\
\text { interview }\end{array}$ & Interviewee roles \\
\hline $\begin{array}{l}\text { C1 } \\
\text { (Lighting) }\end{array}$ & $\begin{array}{l}\text { ETO/MTO/ } \\
\text { SV }\end{array}$ & 10 & $\begin{array}{l}\text { Industrialization head, NPD manager, Design engineer, } \\
\text { Production technician, Product and applications manager, } \\
\text { Production manager, Project manager, Production Manager }\end{array}$ \\
\hline $\begin{array}{l}\text { C2 } \\
\text { (Industrial } \\
\text { house } \\
\text { building) }\end{array}$ & ETO & 10 & $\begin{array}{l}\text { Project manager, Project leader- construction site, Purchaser, } \\
\text { Technical Manager, Development engineer (CAD } \\
\text { process/methods), Development engineer (product platform), } \\
\text { Design engineer, Production manager, Production technician, } \\
\text { Production processor }\end{array}$ \\
\hline $\begin{array}{l}\text { C3 } \\
\text { (Outdoor } \\
\text { power } \\
\text { products) }\end{array}$ & SV & 9 & $\begin{array}{l}\text { Project manager, Project sourcing manager, Group manager } \\
\text { Product Lab (R\&D), Engineering manager (R\&D), Lead engineer } \\
\text { (R\&D), Industrialization project manager, Production manager, } \\
\text { Quality process manager, Production technician }\end{array}$ \\
\hline $\begin{array}{l}\text { C4 } \\
\text { Industrial } \\
\text { house } \\
\text { building) }\end{array}$ & ETO & 10 & $\begin{array}{l}\text { Process owner, Product Manager, Project manager- construction } \\
\text { site, Business area manager, Designer, Development engineer- } \\
\text { CAD process, Development engineer-product platform, } \\
\text { Production processor, Production manager, Production technician }\end{array}$ \\
\hline $\begin{array}{l}\text { C5 } \\
\text { (Automotive) }\end{array}$ & ETO/SV & 11 & $\begin{array}{l}\text { Project manager, Method developer, Group manager construction, } \\
\text { Process owner/design manager, Manager Simulation, Production } \\
\text { technical manager, Materials and process engineer, Production } \\
\text { technician, Press shop and injection molding engineers }\end{array}$ \\
\hline
\end{tabular}

Table 1 gives an overview of the number of interviews and interviewee roles that formed the base for the current state mapping. Company 1 (C1) develops and manufactures lighting systems for the public environment, indoor lighting and outdoor lighting. Company 2 (C2) is a construction company that builds schools, daycares, offices etc. Company 3 (C3) is a global multi-brand company that develops, manufactures and sells forest, park and garden 
products for professional use such as chainsaws, cutting machines and robotic lawnmowers. Company 4 (C4) is a construction company that focuses on building houses. Company 5(C5) is a global manufacturer that develops, manufactures and sells products for sports and outdoor activities such as roof racks for cars, strollers, and bike trailers. A total of 50 semistructured interviews were conducted with individuals representing product development, engineering design, production, purchasing and project management. The same set of questions was used for the interview. The interviews were then analysed by the authors and the results are presented in the sections below.

\subsection{Challenges and current state of production preparation and technical solution reuse}

Table 2: Challenges at case companies (Numbers represents the count of respondents who identified the challenge)

\begin{tabular}{|c|c|c|c|c|c|c|c|}
\hline Theme & Challenges & $\mathrm{C} 1$ & $\mathrm{C} 2$ & $\mathrm{C} 3$ & $\mathrm{C} 4$ & $\mathrm{C} 5$ & Total \\
\hline \multirow{6}{*}{ Development } & Development time & 6 & 1 & 4 & 3 & 6 & 20 \\
\hline & Development costs & 1 & 2 & & & 1 & 4 \\
\hline & Lifecycle perspective & & 1 & 1 & 1 & & 3 \\
\hline & Supplier lead times/ Supplier changes & 1 & & & 1 & & 2 \\
\hline & Early decisions & 2 & & & & & 2 \\
\hline & Reliability of Development time plan & & & & & 1 & 1 \\
\hline Variant & Variant management & 6 & 3 & 4 & 4 & 3 & 20 \\
\hline \multirow{3}{*}{ Requirements } & Standards and regulations & & 1 & 1 & 6 & & 8 \\
\hline & Handling changing requirements & 2 & 2 & & 1 & 1 & 6 \\
\hline & New Technology & 1 & & 1 & & & 2 \\
\hline \multirow{5}{*}{ Knowledge } & Documentation & & & & & 1 & 1 \\
\hline & Incorrect conclusions from early models & & & & & 1 & 1 \\
\hline & Lack of concrete action plan for problem & 1 & & & & & 1 \\
\hline & Human factors and competencies & 1 & & & & & 1 \\
\hline & Lack of information leading to errors & & & 1 & & & 1 \\
\hline \multirow{3}{*}{ Production } & Production system & & & & 3 & & 3 \\
\hline & Late involvement of production & & 1 & & & & 1 \\
\hline & High cost for production changes & & & & 1 & & 1 \\
\hline Planning & Multiple projects/Resource allocation & 3 & & & & 1 & 4 \\
\hline Automation & Automation of industrialisation process & & & & & 1 & 1 \\
\hline Communication & Communication between design and production & 1 & & & & & 1 \\
\hline Standardisation & Standardised way of working & & & & 1 & & 1 \\
\hline
\end{tabular}

The companies currently have no formal product platform strategy. They have identified it as a highly interesting field and some have tested but not found a way forward. The traditional way of platform development poses challenges as it requires high investment at the same time as the need to fulfil unique requirements, be able to quickly introduce new technology, adapt to new legalisation and sometimes optimise performance. Table 2 shows 
the challenges faced during product development. The numbers in table 2 represent the number of respondents who identified the particular challenge. There was a consensus among the companies regarding the challenges faced and development areas. Development time, variant management, changing standards and regulations and changing requirements were identified by all five companies as challenges they need to handle. Development time was a challenge as it created the need to prioritize between projects. Also, it created uncertainties due to changes in requirements and resources like people. Variant management was a challenge because of the large number of articles and the complexity it creates in manufacturing. Automation, communication, competence development, digitalization and information management were identified as the top development areas needed to handle these challenges.

Table 3 gives an overview of the asset reuse in the companies. It was necessary to understand the current level of reuse of technical solutions and knowledge as it forms the base for the development of the platform. They reuse standard components, component libraries in CAD or PLM systems, previous models and knowledge reuse through documents such as guidelines and lessons learned. The reuse of solutions and knowledge is dependent on the skills of the individual.

Table 3. Methods of asset reuse (Numbers represents the count of respondents who identified the challenge)

\begin{tabular}{|l|l|l|l|l|l|l|l|}
\hline Category & Reused item & C1 & C2 & C3 & C4 & C5 & Total \\
\hline \multirow{5}{*}{ Documents } & Guideline document (Procedures and methods) & 3 & 1 & 9 & 2 & 3 & 18 \\
\hline & Lessons learned document & 3 & 3 & 6 & & 4 & 16 \\
\hline & Standard sheets & & 7 & & & & 7 \\
\hline & Checklists (DFX,design reviews etc) & 4 & & & & 1 & 5 \\
\cline { 2 - 6 } & Deviations/ disruption reports & & 2 & & 2 & & 4 \\
\cline { 2 - 6 } & Project review & & 1 & & & & 1 \\
\hline \multirow{5}{*}{ Human factor } & Human competencies (experience, knowledge) & 5 & 3 & 2 & 3 & 6 & 19 \\
\hline & Sharing knowledge through meetings & 4 & 1 & 1 & 6 & 3 & 15 \\
\hline & Team to capture knowledge & 1 & & & 2 & 5 & 8 \\
\hline \multirow{5}{*}{ Models } & Start from previous CAD model & & 2 & 3 & 4 & 3 & 12 \\
\hline & Libraries in CAD/PLM & 3 & 3 & 1 & & 1 & 8 \\
\hline & CAD templates & & 2 & & 3 & 1 & 6 \\
\hline & Calculation model & 1 & 1 & 2 & 1 & 1 & 6 \\
\hline & Standard Dimensions & & 1 & & 2 & & 3 \\
\hline & Test models & & 1 & 1 & & 1 & 3 \\
\hline & Simulation code & & 3 & 7 & 8 & 28 \\
\hline \multirow{5}{*}{ Components } & Component/Solution reuse & & 1 & 1 \\
\hline
\end{tabular}

Production preparation and integration between product development and production mainly happens through communication between design and production engineers. The integration process is embedded in the development process. There are meetings, checklists and workshops that enable production preparation and integration but the efficiency of this process is individual dependent. A need for production awareness among design engineers 
has been identified. The opportunity lies in automating this process and increasing the accessibility of information through digital tools. The interview summary for production preparation and integration is given in table 4.

Table 4. Production preparation and challenges faced

\begin{tabular}{|c|c|}
\hline Company & Ways of production preparation and integration between product development and production \\
\hline $\mathrm{C} 1$ & $\begin{array}{l}\text { Integration method is established in their development process. There is a cross-functional team with } \\
\text { a production representative to give a producibility assessment. There are dialogues and brainstorming } \\
\text { activities during the development phase. Designers have access to manufacturing methods. Checklists } \\
\text { such as design reviews and construction walkthroughs and prototypes are used to ensure integration } \\
\text { and producibility. Production software is used to load the products onto the production stations. } \\
\text { Performance indicators are monitored throughout the process. The challenges faced are not having } \\
\text { people with the right skills and production is not flexible. Opportunity lies in the automatic transfer } \\
\text { of information, utilization of DFA and DFM, improving transparency and communication. }\end{array}$ \\
\hline $\mathrm{C} 2$ & $\begin{array}{l}\text { The production department is involved early in the development process. There are meetings such as } \\
\text { heads-up meeting, kick-off meetings and drawing reviews to ensure production preparation. The } \\
\text { proven solutions are added to standard sheets. Problems arising during production are conveyed to } \\
\text { the drawing departments through feedback where improvements are made. The efficiency of } \\
\text { production preparation is person dependent. They face issues with customization and competence. } \\
\text { Areas of improvement identified are standardization, collecting information from customers, digital } \\
\text { BIM models and better communication between design and production. They also need to automate } \\
\text { the preparation process and presently there are some automation for activities such as generating } \\
\text { cutting lists from BIM software }\end{array}$ \\
\hline $\mathrm{C} 3$ & $\begin{array}{l}\text { The new product development (NPD) process includes dialogues with production and suppliers. A } \\
\text { manufacturing representative is present in the NPD process. They use knowledge from suppliers, cost } \\
\text { engineers and commodity managers. Manufacturability is assessed through drawing reviews, 3P- } \\
\text { workshops, PFMEA and DFA. They need digital tools to ease communication and bring production } \\
\text { strategy into the design by creating awareness within R\&D. There is a redesign loop at the later stages } \\
\text { to correct any mistakes. Opportunity lies in integrated information, automation and competence } \\
\text { improvement. }\end{array}$ \\
\hline $\mathrm{C} 4$ & $\begin{array}{l}\text { Ensures manufacturability through the development process. There are interactions between designers } \\
\text { and production engineers. They have } 3 \mathrm{D} \text { models and control files for production lines for the elements } \\
\text { being manufactured. This data can be exported to the ERP system. A cross-functional team makes } \\
\text { rough mockups and does test runs. They need a better platform for documenting and sharing } \\
\text { information. Opportunity lies in digitalization, automation and standardization. }\end{array}$ \\
\hline $\mathrm{C} 5$ & $\begin{array}{l}\text { Integration is controlled by the product development process and production preparation is ensured at } \\
\text { the third gate of the process where they decide on procurement of equipment and allocation of } \\
\text { resources. There is a production representative in the project and continuous dialogues take place } \\
\text { between the designers and production engineers. The project group is cross-functional and has } \\
\text { representatives from project management, design, production, quality and testing departments. Risk } \\
\text { analysis, FMEA, DFM, DFA, checklists and prototypes are used. Training and workshops are } \\
\text { conducted to increase alignment between the design and production departments. Simulations, better } \\
\text { structure for design reviews, a design that supports automation and flexibility, early supplier } \\
\text { involvement and training for new employees are the identified improvement areas. }\end{array}$ \\
\hline
\end{tabular}

\section{Analysis and future research directions}

The current state study showed that companies do not have a formal product platform strategy but it is identified as an interesting field. Development time, variant management and requirements management are the main challenges faced by all the case companies. Though the challenges faced are similar, the industrial house building companies are influenced more by external changes such as standards and regulations. Christensen et al. [1] 
and Han et al. [16] identified the challenges as gradual determination of product characteristics, product variations, uncertainties in markets, customer requirements, technologies, policies, and regulations. These were in line with the challenges identified from the current state of practice and Han et al. [16] propose a platform approach to overcome these. Improvements in the areas of communication, automation, digitalization, information management, standardization, flexibility and adaptability of systems were needed to meet the challenges. The technical solution reuse happens through component libraries with standard components, documents such as standard sheets and design reviews, knowledge banks of guidelines and procedures, lessons learned documents and rules defined on drawings. Integrations between design and production happen mostly through communication, meetings, standard sheets, checklists, prototypes and there is a production representative in the development team in most cases. The challenges faced both in solution reuse and production preparation is that it happens through communication and is dependent on the individual's competence.

Producbillity consideration during the product development process is important to improve quality and reduce cost [35]. Design engineers should know the manufacturing capabilities of the company to achieve this [24]. The production preparation process and solution reuse in the case companies are dependent on the skills and knowledge of individuals which limits its efficiency. A platform strategy can improve the reuse of design and production information [36]. The literature review helped in identifying the different platforms strategies and concepts that can support in developing product platform means to enhance producibility in the industry. The uncertainty-oriented product platform (UOPP) [16] and the design platform (DP) [21] approaches with flexible elements [18] may help in managing changing requirements from customers, market and legal. The concept of SetBased Concurrent Engineering (SBCE) supports reuse and knowledge development which helps to improve future development projects and production preparation as both design and production teams prepares the feasible set of solutions together [29]. Digitalization and design automation methods can be used to introduce manufacturing inputs into the design process. Stejpandić et al [37] and Levandowski et al. [38] showed how integration of computer-aided drawing (CAD), product data management (PDM), enterprise resource planning systems (ERP) and product configurators can support optimization and analysis of new products. These along with the automated producibility assessment technique [28] shows how digitalisation and design automation can be used for capturing and reusing product and process knowledge. The concept of digital twin can also be explored as it supports the conceptual design, detailed design, and virtual verification [34].

New knowledge in product platform development could enable the companies to increase their competitiveness by supporting the design and development of changeable product platform. Future research work will focus on understanding the challenges faced in the industry to ensure producibility and how the changeable product platform can support to overcome these challenges. The changeable product platform may be based on the combination of product platforms, SBCE, digitalisation and design automation. This will allow the proposed platform to be able to meet the changing requirements and new technology development. Integration with the production is pro-actively coordinated in such a platform by accomodating/controlling the critical production aspects using design/engineering assets, digitalisation and automation. This platform can also support means to guide towards and/or asses producibility. Means for improved understanding of the interfaces between product and production systems, current producibility failures and constraints across design and production are also needed. The current state of practice analysis has shown that there is a base for platform implementation with some solution reuse 
and manual production preparation. This gives an opportunity for implementing a changeable product platform concept to assess producibility and production preparation through the support of digitalisation and design automation tools.

\section{Conclusions}

The purpose of the paper was to identify the challenges, current state of practice concerning producibility and production preparation in the case companies. Also, to identify how critical production aspects can be accommodated/controlled by the design of the product platform for efficient manufacturing through a literature survey. The case companies did not have a formal platform strategy and had some manual production preparation methods. The solution reuse was mostly restricted to components/designs and knowledge reuse happens through meetings or documents. The literature study helped to identify concepts of product platforms such as flexible and adaptable platforms which along with SBCE, producibility, design assets, digitalization and design automation can be used to develop a platform concept that can support producibility enhancement. This can help the companies to be competitive through reduced development time and better adaptability towards changes.

\section{Acknowledgements}

We would like to thank the participating companies, the respondents, the IDEAL project group, the Swedish Knowledge Foundation and the SPARK environment at Jönköping university for their support.

\section{References}

[1] B. Christensen and T. D. Brunoe, Product Configuration in the ETO and Capital Goods Industry: A Literature Review and Challenges, in S. Hankammer et al. (eds.) Customization 4.0, 2018, pp. 423-438.

[2] C. Levandowski, D. Raudberget and H. Johannesson, Set-Based Concurrent Engineering for Early Phases in Platform Development, Advances in Transdisciplinary Engineering, Vol. 1, 2014, pp. 564-576.

[3] S. M. Ferguson, A. T. Olewnik and P. Cormier, A review of mass customization across marketing, engineering and distribution domains toward development of a process framework, Research in Engineering Design, 2014, pp. 11-30.

[4] D. V. Khadilkar and L. A. Stauffner, An Experimental Evaluation of Design Information Reuse During Conceptual Design, Journal of Engineering Design, 1996, pp. 331-339.

[5] D. Robertson and K. Ulrich, Planning for Product Platforms, Sloan Management review, 1998, pp. 19-31.

[6] O. Battaïa, A. Dolgui, S. S. Heragu, S. M. Meerkov and M. K. Tiwari, Design for manufacturing and assembly/ disassembly: joint design of products and production systems, International Journal of Production Research, 2018, Vol. 56, pp. 7181-7189.

[7] J. Madrid, J. Landahl, R. Söderberg, H. Johannesson and J. Lööf, Mitigating risk of producibility failures in platform concept development, 31st Congress of the International Council of the Aeronautical Sciences, ICAS 2018, 2018, https://www.icas.org/ICAS_ARCHIVE/ICAS2018/data/papers/ICAS2018_0101_paper.pdf.

[8] L. Hvam, N. Mortensen and J. Riis, Product Customization, Springer-Verlag, Berlin Heidelberg, 2008.

[9] K. T. Ulrich and S. D. Eppinger, Product Design and Development, McGraw-Hill, Irwin, 2012.

[10] T. W. Simpson, Z. Siddique and R. J. Jiao, Product platform and product family design: methods and applications, Springer Science \& Business Media, Berlin, 2006.

[11] M. Bonev, M. Wörösch and L. Hvam, Utilizing platforms in industrialized construction: A case study of a precast manufacturer, Construction Innovation, 2015, Vol. 15, No. 1, pp. 84-106.

[12] B. Hansen, Development of industrial variant specification systems, IKON Tekst \& Tryk A/S, 2003. 
[13] S. André, F. Elgh, J. Johansson and R. Stolt, The design platform-a coherent platform description of heterogeneous design assets for suppliers of highly customised systems, Journal of Engineering Design, 2017, pp. 599-626.

[14] K. Safsten, G. Johansson, N. Lakemond and T. Magnusson, Interface challenges and managerial issues in the industrial innovation process, Journal of Manufacturing Technology Management, 2014, pp. 218-239.

[15] M. T. Michaelis, H. Johannesson and H. A. Elmaraghy, Function and process modelling for integrated product and manufacturing system platforms, Journal of Manufacturing Systems, 2015, pp. 203-215.

[16] X. Han, R. Li, J. Wang, G. Ding and S. Qin, A systematic literature review of product platform design under uncertainty, Journal of Engineering Design, pp. 266-296, 2020.

[17] E. S. Suh, Flexible Product Platform, Ph. D. Thesis, Engineering Systems Division, Massachusetts Institute of Technology, 2005.

[18] E. S. Suh, O. L. de Weck and D. Chang, Flexible product platforms: framework and case study, Research in Engineering Design, 2007, pp. 67-89.

[19] G. Schuh, M. Lenders and J. Arnoscht, Focussing product innovation and fostering economies of scale based on adaptive product platforms, CIRP Annals - Manufacturing Technology, 2009, pp. 131-134.

[20] D. Raudberget, F. Elgh, R. Stolt, J. Johansson and M. Lennartsson, Developing agile platform assets Exploring ways to reach beyond modularisation at five product development companies, International Journal of Agile Systems and Management, 2019, Vol. 12, No. 4, pp. 311-331.

[21] S. André and F. Elgh, Modeling of transdisciplinary engineering assets using the design platform approach for improved customization ability, Advanced Engineering Informatics, 2018, Vol. 38, No. July, pp. 227-290.

[22] S. Ramakrishnan and M. V. Testani, "An integrated lean 3P and modelling approach for service and product introduction, Proceedings IIE Annual Conference, Norcross, 2011, pp. 1-8.

[23] J. Landahl, C. Levandowski, H. Johannesson and O. Isaksson, Assessing producibility of product platforms using set-based concurrent engineering, Advances in Transdisciplinary Engineering, Vol. 3, 2016, pp. 35-44.

[24] S. Gedell, M. T. Michaelis and H. Johannesson, Integrated model for co-development of products and production systems - A systems theory approach, Concurrent Engineering Research and Applications, 2011, pp. 139-156.

[25] C. Poli, Design for Manufacturing, Butterworth-Heinemann, Boston, 2001.

[26] S. Yang and Y. F. Zhao, Additive manufacturing-enabled design theory and methodology: a critical review, International Journal of Advanced Manufacturing Technology, 2015, Vol. 80, No. 1-4, pp. 327-342.

[27] S. Shukor and D. A. Axinte, Manufacturability analysis system: Issues and future trends, International Journal of Production Research, 2009, pp. 1369-1390.

[28] T. Heikkinen, R. Stolt, F. Elgh and P. Andersson, Automated Producibility Assessment Enabling Set-Based Concurrent Engineering, Advances in Transdisciplinary Engineering, 2016, Vol. 3, pp. 947-956.

[29] D. K. Sobek, A. C. Ward and J. K. Liker, Toyota's Principles of Set-Based Concurrent Engineering, Sloan Management review, 1999, https://sloanreview.mit.edu/article/toyotas-principles-of-setbased-concurrentengineering/, Accesed July, 12021.

[30] D. Raudberget, Practical Applications of Set-Based Concurrent Engineering in Industry, Journal of Mechanical Engineering, 2010, pp. 685-695.

[31] M. Cederfeldt and F. Elgh, Design automation in SMEs - Current state, potential, need and requirements, CED 05, the 15th International Conference on Engineering Design, 2005.

[32] S. Hallstedt, O. Isaksson and A. Öhrwall Rönnbäck, The Need for New Product Development Capabilities from Digitalization, Sustainability, and Servitization Trends, Sustainability, 2020, Vol. 12, No. 23, 10222.

[33] H. Lasi, P. Fettke and H. Kemper, Industry 4.0, Business \& Information Systems Engineering, 2014, Vol. 6, No. 4, pp. 239-242, https://aisel.aisnet.org/bise/vol6/iss4/5, Accesed July, 12021.

[34] F. Tao, J. Cheng, Q. Qi, M. Zhang, H. Zhang and F. Sui, Digital twin-driven product design, manufacturing and service with big data, International Journal of Advanced Manufacturing Technology, 2018, Vol. 94, pp. 3563-3576.

[35] J. Madrid, Design for Producibility in Fabricated Aerospace Components Department of Industrial and Materials Science, Ph.D. Thesis, Department of Industrial and Materials Science, Chalmers University of Technology, Gothenburg, 2020.

[36] J. Landahl, Platform Design for Producibility, Ph.D. Thesis, Department of Industrial and Materials Science, Chalmers University of Technology, Gothenburg, 2018.

[37] J. Stjepandić, E. Ostrosi, A. J. Fougères and M. Kurth, Modularity and supporting tools and methods, in J. Stjepandić et al. (eds.) Concurrent Engineering in the 21st Century: Foundations, Developments and Challenges, Springer International Publishing Switzerland, 2015, pp. 389-420.

[38] C. E. Levandowski, Platform Lifecycle Support using Set-Based Concurrent Engineering, Ph.D. Thesis, Department of Product and Production Development, Chalmers University of Technology, Gothenburg, 2014. 